\title{
Categorizing Sources of Risk and the Estimated Magnitude of Risk
}

\author{
Juan Ignacio Aragonés ${ }^{1}$, Emilio Moyano², and Fernando Talayero ${ }^{3}$ \\ ${ }^{1}$ Universidad Complutense de Madrid \\ ${ }^{2}$ Universidad de Talca (Chile) \\ ${ }^{3}$ Universidad de Castilla-La Mancha
}

The social perception of risk is considered a multidimensional task, yet little attention has been paid to the cognitive components that organize sources of risk, despite their having been discovered in various research studies. This study attempts to concretely analyze the cultural dimension involved in those processes. In the first phase, we tried to discover to what extent sources of risk are organized into the same categories by people from different countries. In order to do so, two groups of participants were formed: 60 Spanish psychology students and 60 Chilean psychology students classified 43 sources of risk into different groups according to the criteria they found appropriate. The two samples classified risk into identical groups: acts of violence, drugs, electricity and home appliances, household chemicals, chemicals in the environment, public construction projects, transportation, sports, and natural disasters. In a second study, 100 Spanish and 84 Chilean students were asked to evaluate the magnitude of the damage incurred by 17 sources of risk. In both groups, it was observed that the evaluation of damage resulting from each source of risk was affected by its category.

Keywords: risk, risk perception, categorizing risk, evaluation of risk, risk management, disasters

\begin{abstract}
La percepción social del riesgo se considera una tarea multidimensional, sin embargo se ha prestado poca atención a los componentes cognitivos que organizan las fuentes del riesgo, a pesar de que se han descubierto en varios estudios de investigación. Concretamente, este estudio intenta analizar la dimensión cultural implicada en esos procesos. En primer lugar, intentamos descubrir hasta qué punto personas de diferentes países organizan las fuentes de riesgo en las mismas categorías. Para ello, se formaron dos grupos de participantes: 60 estudiantes de psicología españoles y 60 estudiantes de psicología chilenos clasificaron 43 fuentes de riesgo en diferentes grupos según los criterios más apropiados para ellos. Las dos muestras clasificaron el riesgo en grupos idénticos: actos de violencia, drogas, electricidad y electrodomésticos, productos químicos domésticos, productos químicos en el medioambiente, proyectos de construcción públicos, transporte, deportes y desastres naturales. En un segundo estudio, 100 estudiantes españoles y 84 chilenos evaluaron la magnitud del daño provocado por 17 fuentes de riesgo. En ambos grupos, se observó que la categoría afectaba la evaluación del daño resultante de cada fuente de riesgo.

Palabras clave: riesgo, percepción de riesgo, categorización de riesgo, evaluación de riesgo, manejo de riesgo, desastres
\end{abstract}

Correspondence concerning this article should be addressed to Juan Ignacio Aragonés, Departamento Psicología Social, Facultad de Psicología, Universidad Complutense de Madrid, Campus de Somosaguas, 28223, Madrid. Phone: +34-913942910 Fax: +34-913943189. E-mail: jiaragones@psi.ucm.es 
From Fischhoff et al.'s first study (1978) to Neto and Mullet's more recent one (2000), a great deal of research has employed the psychometric model of risk perception developed by the Oregon Group, as Puy (1995) and Slovic (2000a) iterated in their revisions. Those revisions illuminate how studies that use that model repeat one another by applying the same methodology in order to obtain, through a factorial analysis, the dimensions that group characteristics supposedly related to risk perception, such as the willingness of an individual to take a risk, the degree of understanding and control he or she has over it, and the immediacy or gravity of it. Essentially, this study has sought to understand the dimensions by which the average person organizes the risk they perceive, without taking heed of between-subjects variability (Barnett \& Breakwell, 2001). Nevertheless, from that approximation there have hardly been any systematic studies about categorizing sources of risk, although that subject is of great interest in the context of applied psychology, as indicated by Morgan et al. (2000). Thus, the management of risk by different organizations, both public and private, would be improved if there were access to the categorizations of risk that people make on their own. This would allow them to plan risk management with an understanding of the distinct, empirical types of sources of risk, and their corresponding characteristics.

From a theoretical perspective, studying the average person's categorization of sources of risk is interesting because it allows us to understand the attributes by which certain sources of risk are classified into categories, and how certain dimensions of those different categories operate.

Some exceptions arose in the early days of this area of research through the attempts of some studies to establish taxonomies of sources of risk, as was discussed in Cvetkovich and Earle's revision (1985), who traced the "story of the natural life of sources of risk." They established three criteria for classifying risk: its original cause, its physical and psychosocial characteristics, and the type of individual or group behavior it sets in motion. At that time, some empirical field experiments had been conducted, such as Vlek and Stallen's (1981) and Johnson and Tversky's (1983, 1984). The latter observed that the average person organize sources of risk into categories, and that those categories are related to the perception of the damage that could be done by a given risk. Along those lines, Puy and Aragonés (1992) came up with two categories for sources of risk - "low control-low probability-high consequence" and "high control-high probability-low consequence"- by analyzing the responses participants gave as to whether or not they felt personally exposed to those risks.

Along the same line of argument as the work of Johnson and Tversky $(1983,1984)$, the present study has involved two studies run consecutively. In the first, we tried to discern whether or not members of different urban societies classified sources of risk into the same categories, without indicating to them in the process any criteria for classifying the given risks.
Three variables were observed in this study that relate to those used by Johnson and Tversky (1983, 1984). First, the number of sources of risk used in the first study is much greater than in their study. Second, the present study involved classifications by two different societies, as opposed to within a single society. Third, the process used in our second study was much simpler than the one used by Johnson and Tverksy (1984), seeing as how this study simply asked participants to complete a direct estimation of the magnitude of damage incurred by each source of risk, while they, in addition to the initial estimation we asked for, operating under the assumption that some of the risks would first be underestimated by the participants, requested a second estimation from participants.

In order to achieve the proposed objectives, it was necessary that the sources of risk submitted to classification be easily recognizable to participants in order to ensure that the categories were not assigned randomly. Thus, one should look for different populations that consider the same set of sources of risk to cause meaningful damage. Specifically, we looked to Chilean and Spanish populations, given that both meet that condition, as was observed in a study by Aragonés, Talayero, and Moyano (2003). On the other hand, in order to avoid the potential differences that may stem from pertaining to one nationality versus another, we worked with samples with a high level of instruction, which Bontempo, Bottom, and Weber (1997) suggest, and we also homogenized the samples in terms of age and living environment.

In summary, we sought to discover whether or not people from two different cultural contexts, but with similar sociodemographic characteristics, would classify sources of risk into the same categories, and if that would affect their evaluation of the magnitude of the potential damage incurred by those risks.

\section{First Study \\ Method}

\section{Participants}

We worked with two similar samples of Chilean and Spanish students residing in an urban environment that voluntarily completed the sample in testing locations equipped with the furniture necessary to carry out the classification. The first was composed of 60 psychology students at the Universidad Complutense of Madrid, and the second by 60 psychology students at the Universidad of Santiago, Chile. The gender variable was distributed the same way in both samples, with $50 \%$ male and $50 \%$ female subjects. The mean age of the subjects was 20.4 years old $(S D=1.48)$ in the Spanish sample, and 20 years old $(S D=$ 1.4) in the Chilean sample. 


\section{Instruments}

To achieve the objective of the first study, we designed a questionnaire identical in format for the participants from both countries, although the editions were slightly different due to linguistic variations. Along with the registration form to record personal variables and the instructions to carry out the test, each participant was given a set of $4310.5 \times 7 \mathrm{~cm}$. cards. On each, a source of risk was written. The task was to classify the cards into various piles according to the following instructions:

Before you is a group of cards and on each, a different risk appears. These are activities, technologies, substances and events that could directly or indirectly cause damage, serious loss, or even death in real life, either immediately or in the long term. Please make piles with the cards as you see fit, keeping in mind that each pile should be formed by the risks that you believe share a common characteristic that is distinct from the common characteristics of the other piles. Take as much time as necessary.

The sources of risk that appeared on the cards were selected from those most feared in Spanish and Chilean urban societies, obtained through the same technique in two prior studies in Spain (Puy, 1995) and Chile (Aragonés, Talayero, \& Moyano, 2003). The set consisted of the 43 risks perceived as most dangerous by samples from both countries; the samples coincided in evaluating them as such more than $30 \%$ of the time in one sample, and more than $20 \%$ of the time in the other.

\section{Results}

The groupings done by participants were in some cases similar and in other cases dissimilar. For some sources of risk, we saw that to a great extent, they were placed within the same group or category, while in others, on the contrary, the differences between the groups were so great that sources of risk were classified into different groups. To determine whether or not there are categories of risk that people use to structure the risk in their lives, and to see to what extent those impressions are shared among urban societies in both countries, a cluster analysis was performed, grouping the sources of risk done by each samples in a matrix $\left(n_{-} n\right)$ where $n_{\mathrm{i}}$ was each of the sources of risk presented on the cards and the value of $n_{i j}$ was the number of participants that grouped the sources $i$ and $j$.

The results displayed in Figures 1 and 2 show a strong similarity between the two dendrograms, although certain, small differences are also seen. The categories that emerged from the analysis were the following: acts of violence (associated in Chile with popular movements), drugs (in Spain, also associated with popular movements), electricity and home appliances, household chemicals, chemicals in the environment, public construction projects, transportation, sports and natural disasters.
If the two dendrograms are carefully observed, it is apparent that the nodes corresponding to household chemicals and chemicals in the environment are grouped together on a higher-level node called pollution in which sources of risks that contaminate the environment are included.

Next, in the higher-level grouping, there are two differentiated nodes that combine the same lower-level nodes in the samples from both countries. The first node combines transportation with public construction projects on the one hand, and occupation with sports on the other to create a supercategory called equipment and human activity. The second node groups electricity and home appliances with pollution in a supercategory called use and transformation of energy. Meanwhile, these two supercategories are clearly different from the others, which are concretely defined as natural disasters, drugs and acts of violence.

\section{Discussion}

The categories yielded by the groupings performed by samples from both Spain and Chile are practically identical. The only apparent difference between their two respective dendrograms is in subjects' associations with the popular movements category, which were distinctive in each country. While the Spanish participants associate them with drugs, Chileans associate them with acts of violence, which could be explained by the different social representations each society has for that type of event. However, this cultural difference does not hinder the generalizability of the results of this study in that there needs to be a discussion about the kinds of risk that is widely shared by participants from both countries.

If the results of this study are compared with those of Johnson and Tversky's research (1983), it may be observed that the categories obtained in both are similar. Those authors, from eighteen sources of risk they presented to students in the United States, came up with categories such as natural disasters, transportation accidents, acts of violence, technological disasters and illness. The number of risks and the specific sources of risk used in each study make it so that the category labels used in some cases do not correspond and in others appear new. For example, in this study, no illness was included. However, in the Johnson and Tversky study, five were included, which caused that category to emerge in a noticeable way. Likewise, those authors did not include occupation, drugs, or everyday events, products and activities, which inhibits us from seeing those categories reflected in their study. On the other hand, the rest of their categories appear to be represented by two or three sources, so some categories are labeled differently in the two studies. Thus, the category that they call transportation accidents groups the risks of traffic accidents with airplane accidents, while in this study, transportation includes motorcycles, 


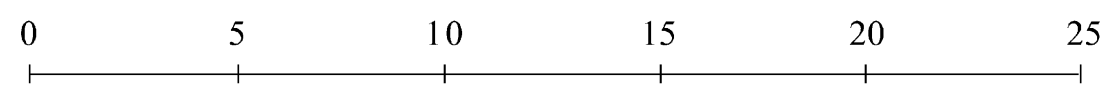

RAPE

TERRORISM

ARMED ROBBERY/ROB.

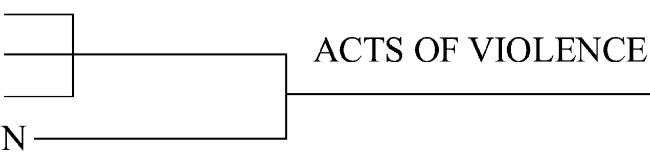

CONVENTIONAL WEAPON

ALCOHOL

TOBACCO

COCAINE

LSD

MARIJUANA

NIGHTCLUB

OUTDOOR CONCERT

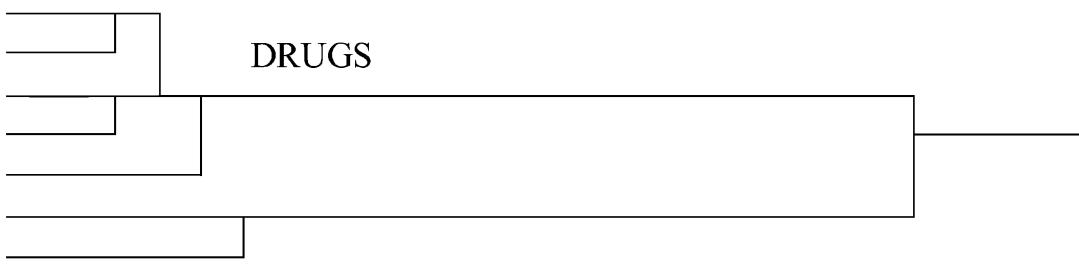

ELECTRONICS

SOCKET

HEATING

ELECTRICITY

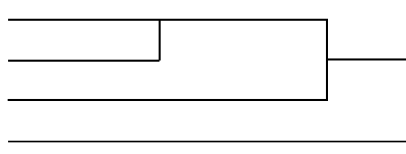

ELECTRICITY \& HOME APPLIANCES

DETERGENTS

BLEACH

INSECTICIDE

AEROSOL

INDUSTRIAL POLL.

AIR POLLUTION

AUTOMOBILE POLL.

OIL

NUCLEAR ENERGY

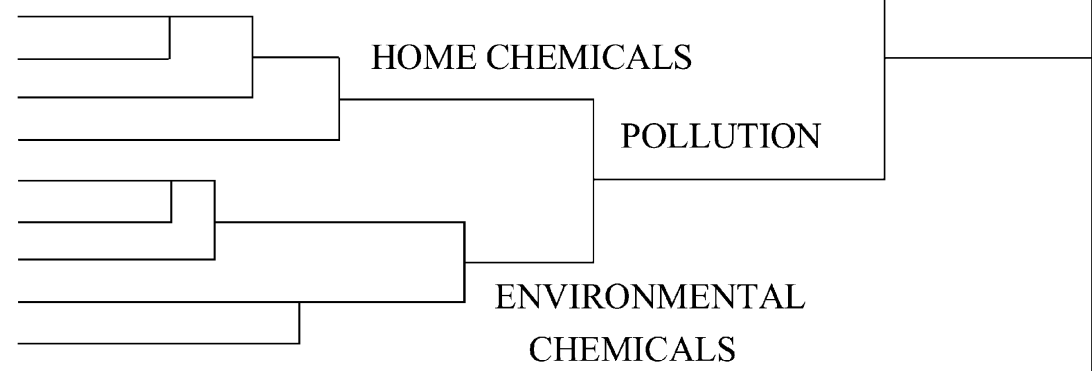

MINE WORKER CONSTRUCTION WORK

SURGEON

BRIDGES

SKYSCRAPERS

ROAD

MOTORCYCLE RACE

CAR

AIRPLANE

BOAT

TRAIN

AUTO RACING

MOTORCYCLE RACE

ROCK CLIMBING

BOXING

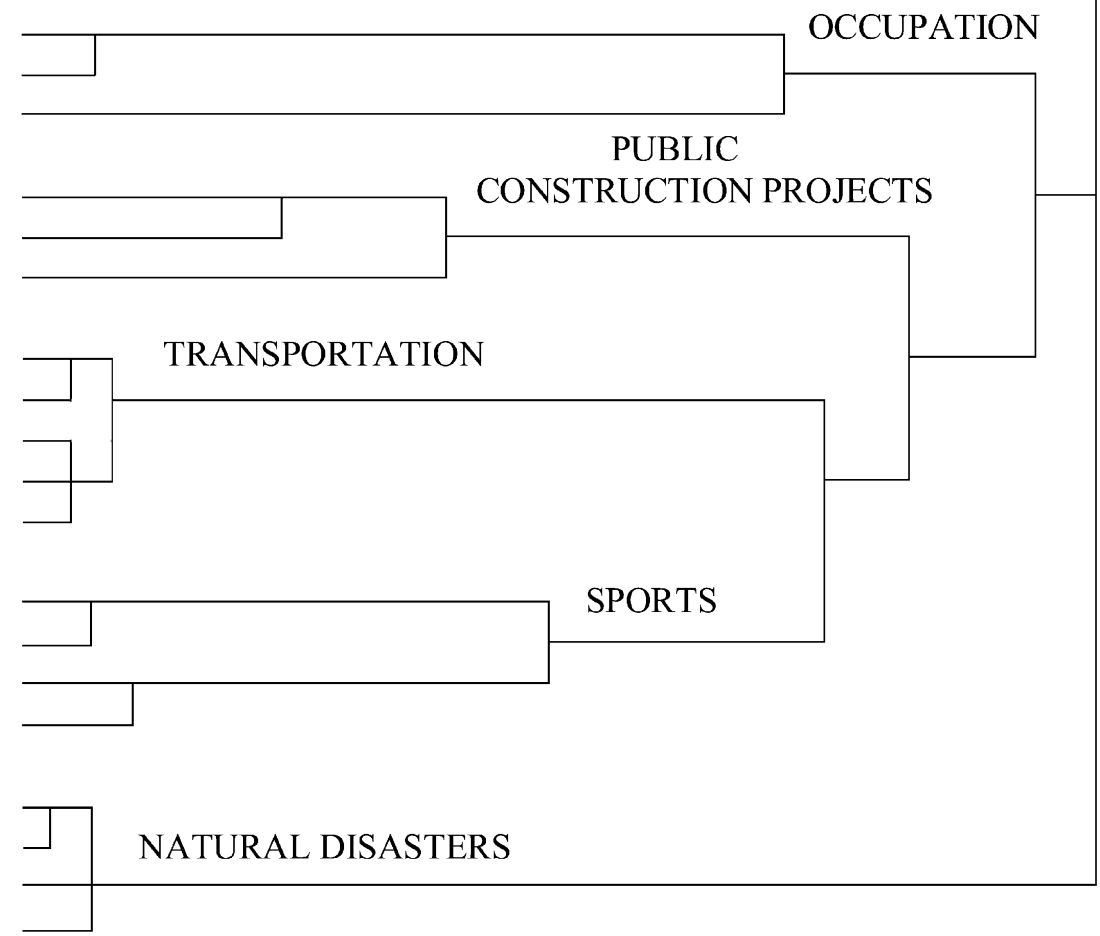




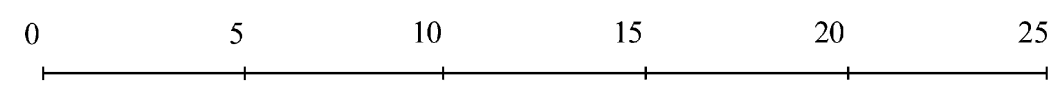

HURRICANE

TIDAL WAVE

TORNADO

FLOOD

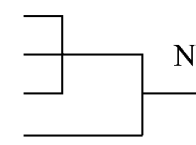

AIRPLANE

BOAT

MOTORCYCLE

AUTOMOBILE

TRAIN

BRIDGE

SKYSCRAPER

ROAD

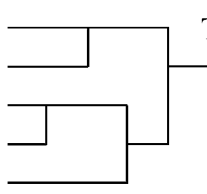

TRANSPORTATION

ATURAL DISASTERS

MINE WORKER

CONSTRUC. WORKER

AUTO RACING

MOTORCYCLING

ROCK CLIMBING

BOXING

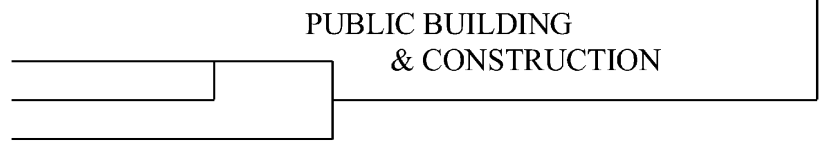

PROFESSIONS

SURGERY

ELECTRONICS

SOCKET

HEATING

ELECTRICITY

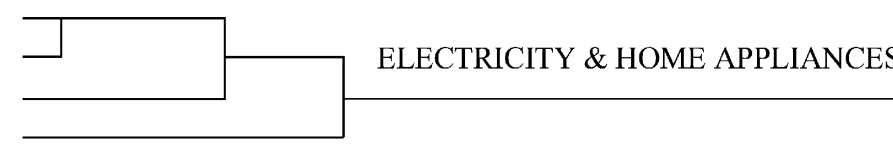

DETERGENTS

INSECTICIDE

AEROSOL

CHLORINE

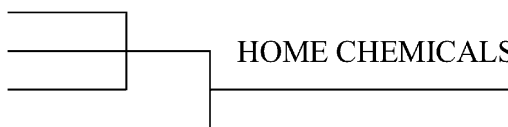

AIR POLLUTION

AUTO. POLLUTION

INDUSTRIAL CONTAM.

OIL

NUCLEAR ENERGY

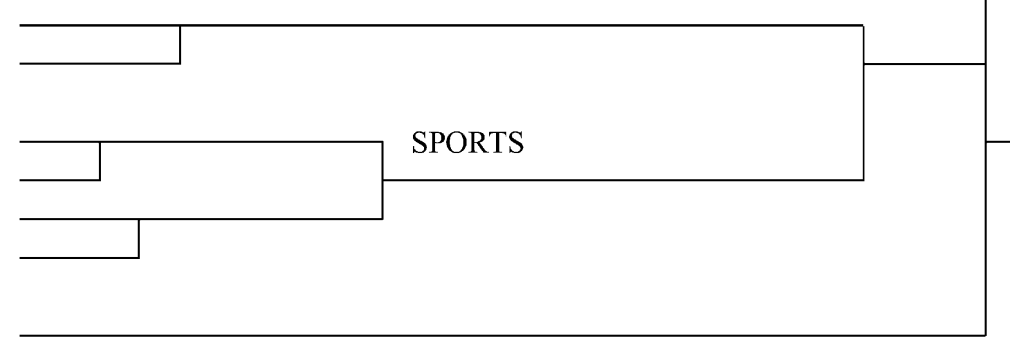

LSD

TOBACCO

MARIJUANA

ALCOHOL

COCAINE

NIGHTCLUBS

CONCERTS

ASSAULT

RAPE

TERRORISM

CONVENTIONAL WEAPON-

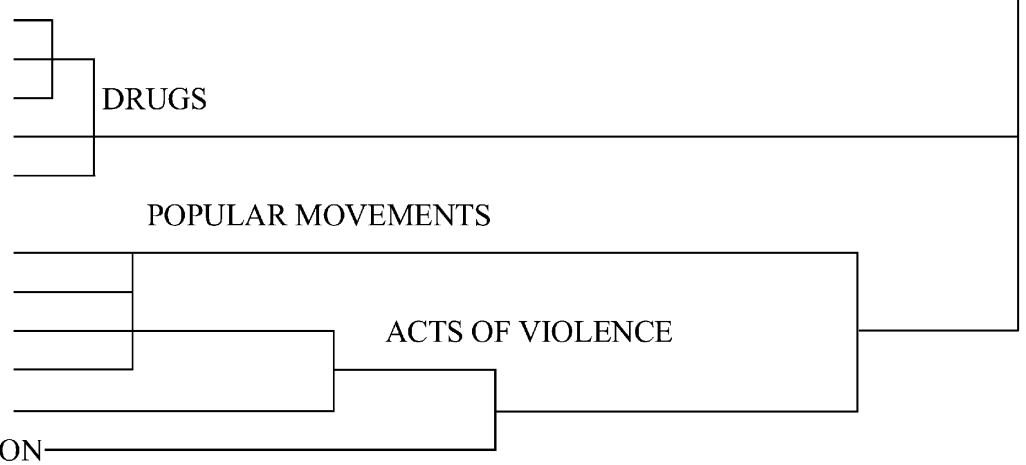

Figure 2. Dendrogram of the cluster analysis of sources of risk produced among Chilean participants. 
automobiles, airplanes, boats and trains. However, that is not the case for acts of violence and natural disasters, which appear in both studies.

For that reason, it may be said that, in light of the results of these studies, which reiterate one another, people organize sources of risk into similar categories, independently of their pertaining to one Western country or another, at least when participants have a high level of education. Lai et al. (2003) obtained results analogous to the findings of this study when they confirmed that sources of risk are organized into categories such as mankind and technology, activities of everyday life and nature, independently of whether they were evaluated as personal, local, or global sources of risk.

Two explanations for these results invite further inquiry into this field of research. The first refers to the fact that the taxonomy of risks obtained in this study may respond to the peculiar way in which people from Western societies perceive the world of classified risk. If this is true, it is important to carry out similar studies with participants from different societies, using a different set of risks, and to see to what extent the same results are obtained.

If the categories are consistent in different parts of the world, then it seems appropriate to study how the dimensions by which characteristics are grouped, traditionally used in order to apply psychometrics, function when one analyzes each category separately, as has been applied to research on nutritional risks (Fife-Schaw \& Rowe, 1996) and nuclear energy (Slovic, 2000b).

If in fact the categories are consistent around the world, then it seems relevant to study how common characteristics used in psychometrics may affect those categories, similarly to what has been done in studies of food-related (Fife-Schaw \& Rowe, 1996) and nuclear energy-related risks (Slovic, 2000b), among others.

The second possible explanation for these results has to do with the need to contrast the categories obtained in this study with those of other domains of everyday life, given that the results presented in this study could be attributed more to a general way of organizing one's surroundings than to a specific manner of organizing risk as Slovic, Fischhoff, and Lichtenstein (1986) suggested, when critiquing the work of Vlek and Stallen (1981) and of Johnson and Tversky (1984).

\section{Second Study}

The results of the previous study have proven that the two groups of participants, pertaining to different societies and countries, organize the same sources of risk into the same categories, supported by similar results obtained by Johnson and Tversky (1984). Once participants had grouped the sources of risk, these authors asked them to evaluate them according to a criterion called "conditional prediction." Specifically, participants were informed that they had evaluated a source of risk as less dangerous than it really was and, given that information, the researchers tried to see if this produced a bias in how the participants would evaluate the sources of risk they had grouped into the same category as the first. The results demonstrated the relevance of attributing a source of risk to a category when people evaluate the magnitude of damage associated with that risk.

Following that line of investigation, the present study tried to observe whether or not participants from different countries slant the perceived magnitude of damage they associate with a certain source of risk as a function of the category in which they had previously classified it with similar items. If this is the case, it would confirm that the grouping of risks by similarity should be taken into account when analyzing participants' estimations of the damage incurred by such risks, which would reject, in part, Slovic, Fischhoff, and Lichtenstein's (1986) critique of this type of grouping, considering that "they may be susceptible to influence from considerations that are not relevant to risk" (p. 10).

\section{Method}

\section{Participants}

The participants that took part in the second study were 184 psychology students -100 Spanish and 84 Chilean- with an average age of 19.6 years $(S D=0.74)$ for the Spanish group and 20.4 years for the Chilean group $(S D=1.46)$. The distribution of gender was $50 \%$ in the Spanish group and $59.5 \%$ women, $40.5 \%$ men in the case of the Chilean group.

\section{Instruments}

In order to fulfill the proposed objective, a selfadministered questionnaire was designed similar to the one Puy (1995) used in his third study in which, in addition to questions about the sociodemographic characteristics of the participants, a list was included of 17 sources of risk chosen randomly from the ones utilized in the prior study. The participants' job was to estimate the magnitude of the damage posed by each one of them.

At the beginning of the questionnaire, the participants were given instructions indicating how to estimate the magnitude of risk. First, they were given 17 cards, one for each source of risk, and they were to order them as a function of the total risk of death each source of risk posed within their society, as was done in the classic experiments that studied risk within the "psychometric paradigm." Next, the participants were asked to assign a score between 0 and 100 to each source of risk that reflected the magnitude of perceived damage as a function of the total risk of death they estimated it to have within their society. 


\section{Results}

In order to confirm whether or not the magnitude of damage attributed to a given source of risk was affected by the category in which it had previously been classified, an analysis of principle components was done with varimax rotation of the magnitudes of damage attributed to the 17 risks by the 184 participants.

The results of the analysis appear in Table 1. In the table, the five dimensions that, with an eigenvalue greater than 1 , account for $66.31 \%$ of the variance. These dimensions, labeled as Traffic, Elements and Events of Daily Life, Pollution, Drugs and Acts of Violence are domains that influence participants' scoring of magnitude, although each does so with a separate, very different magnitude of its own.

In the table, only the weights of magnitudes of risk with a value greater than 0.4 appear, in order to clearly show the risks that comprise each factor. Thus, two risks with elevated weights in two factors stand out: insecticide, which appears in both Elements and Events of Daily Life and Contamination; and cocaine, which appears as clearly linked to Drugs as to Acts of Violence.

The results of the principle components analysis done for each of the groups of participants, and also displayed in Table 1, calls attention to the peculiarities of each group. In the Spanish group, the five factors that account for $66.31 \%$ of the variance are organized in the following order: Pollution, Traffic, Elements and Events of Daily Life, Drugs, and Acts of Violence. Also, each one of those risks separately influences the same factors as the total sample. In the Chilean group, the same five factors account for $69.18 \%$ of the variance, but the order is slightly different: Traffic, Elements and Events of Daily Life, Acts of Violence, Pollution, and Drugs. Lastly, the weight of these three risks is distributed differently than the two prior: electricity, which weighs as heavily on Traffic as on Elements and Events of Daily Life; aerosol, which shares influence over Elements and Events of Daily Life and Pollution; and cocaine, which only influenced Drugs.

\section{Discussion}

The factorial analyses show that the damage magnitudes that people attribute to the 17 sources of risk are organized according to the same structure in the Spanish and Chilean groups alike. The small differences between the groups may be understood as peculiarities specific to each society. In

Table 1

Principle Components Analysis of the "Estimated Magnitude of Risk"

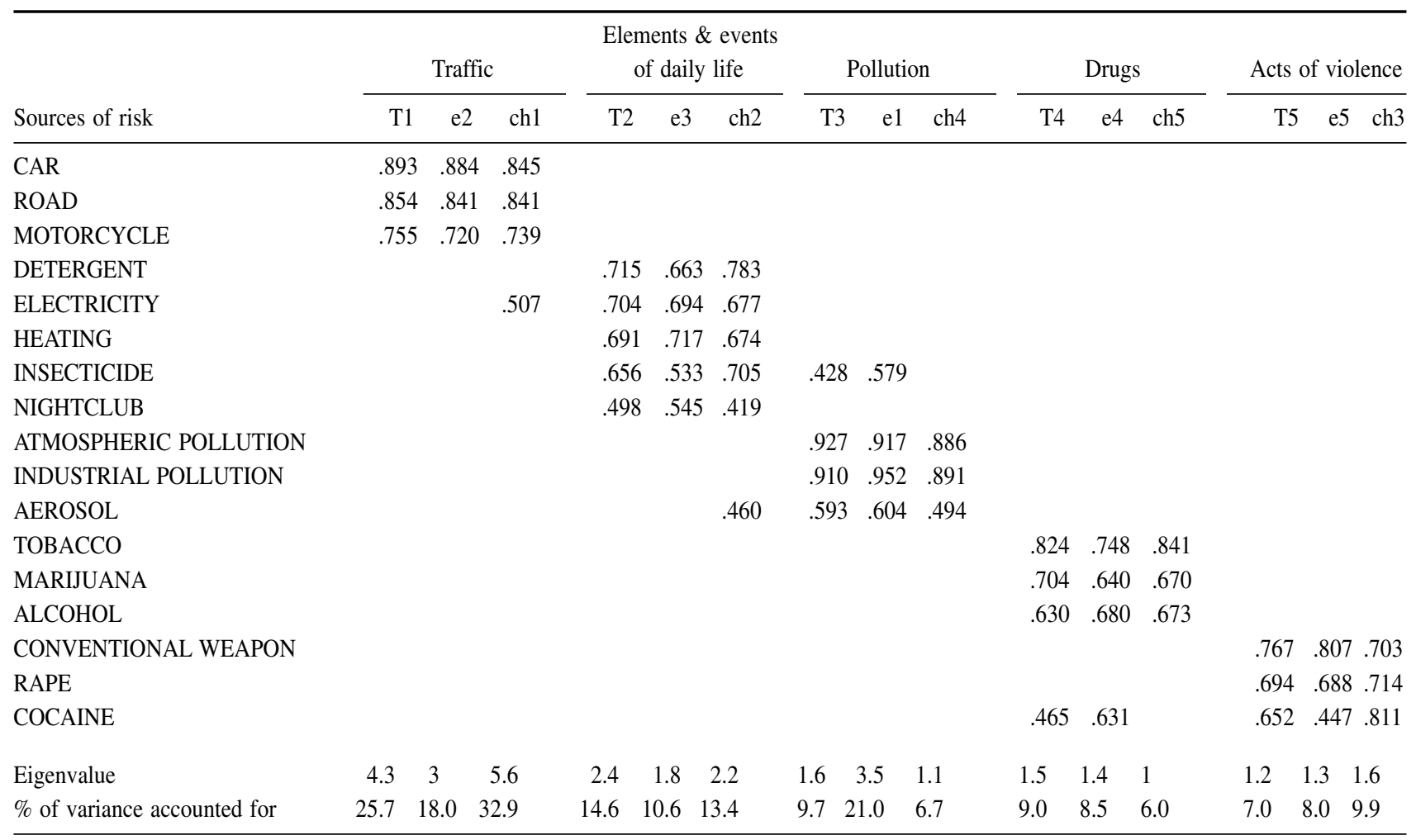

Note. $\mathrm{T} 1$ - T5 = Components that correspond to the total sample $(N=184)$. Total accumulated variance $66.31 \%$.

e1 - e5 = Components that correspond to the Spanish sample $(N=100)$. Total accumulated variance $66.27 \%$.

ch1 - ch5 = Components that correspond to the Chilean sample $(N=84)$. Total accumulated variance $69.18 \%$.. 
the Spanish group, that difference is produced in two sources of risk: insecticide, which weighs upon the Elements and Events of Daily Life factor and the Pollution factor, and cocaine, which simultaneously factors into the Drugs and Acts of Violence categories. In the Chilean group, the difference is produced for electricity, which weighs on the Traffic and Elements and Events of Daily Life categories and aerosol, which influences that category as well as Pollution.

The reduced number of sources of risk utilized in the second study as compared to the first prevents us from seeing a correlation between the categories that emerged in the two studies. However, the dimensions that arose from the factorial analysis of damage magnitude are related to those obtained in the first study, although the assigned category names in both studies differed in some respects.

If the results of the two studies are carefully observed, one may notice that in the structure that arose from the factorial analysis, the configuration produced by the cluster analyses is supported.

For that reason, given the results of both studies, it may be concluded that sources of risk are not perceived in isolation, separately, but as forming a part of domains or categories and also, consequently, the estimated damage magnitude for each risk is not independent of the corresponding category. Similar results were already found in earlier studies, such as Johnson and Tversky's (1984) study in which, using difference research methods, it was observed how certain sources of risk associated with spheres such as illness or acts of violence are perceived with a damage magnitude common to that area.

The multidimensionality of perceiving risk, as maintained in psychometrics, suggests a correlation between the categories that risk is placed into, and the characteristics used in this model. This becomes clear in the distribution of the risks over the two axes in the factorial analysis: misunderstanding and fear (Slovic, 1987). Nevertheless, Slovic (1992) himself suggests that the empirical results of a technical application depend on the sources of risk used, on the characteristics to be evaluated, and on the methods of analysis employed. Thus, it seems relevant to study the perception of risk in this paradigm for each category separately, such that the dimensions obtained are not influenced by the respective weight of risks belonging to other categories. The explanation that allows for this model of perceiving risk would enable the precise identification of the attributes that correspond to a given category and the value that those attributes have for each risk. To that, one might respond that, at least in part, the argument that Morgan et al. (2000) make in suggesting how difficult it is to establish a group of common attributes for all categories.

On the other hand, sources of risk classifications into natural and technological categories and their respective subcategories by experts and written in risk management manuals, have been discredited on numerous occasions for not corresponding to those carried out by laymen (Puy \& Cortés, 2000). However, in this study it was observed that the average person does use some similar categories to those of the experts, at least when they evaluate the damage magnitude of sources of risk.

Given the two aforementioned considerations, it may be concluded that it is relevant to study risk perception according to the psychometric paradigm for each category separately, so that the dimensions obtained are not influenced by risks belonging to other categories within the same dimension during the factorial analyses. The conclusion that allows for a model of risk perception in these terms would allow for more precise recognition of the attributes that correspond to a given category and the influence that they have over each risk.

To conclude, it is fitting to pose a final question, one of methodological concern. It is important to note that there is a need to work with a greater number of sources of risk, even though the number of risks selected in the second study was sufficient to achieve the proposed objectives. It was small and thus left open to interpretation the question of what results would have been obtained if the sources of risk had been the same in both studies.

\section{References}

Aragonés, J. I., Talayero, F., \& Moyano, E. (2003). Percepción del riesgo en contextos culturales diferentes. Revista de Psicología Social, 18, 85-100.

Bontempo, R. N., Bottom, W. P., \& Weber, E. U. (1997). Crosscultural differences in risk perception: A model-based approach. Risk analysis, 17, 479-488.

Barnett, J., \& Breakwell, G. M. (2001). Risk perception and experience: Hazards personality profiles and individual differences. Risk Analysis, 21, 171-177.

Cvetkovich, G., \& Earle, T. C. (1985). Classifying hazardous events. Journal of Environmental Psychology, 5, 5-35.

Fife-Schaw, C., \& Rowe, G. (1996). Public perceptions of everyday food hazards: A psychometric study. Risk Analysis, 16, 487500.

Fischhoff, B., Slovic, P., Lichtenstein, S., Read, S., \& Combs, B. (1978). How safe is safe enough: A psychometric study of attitudes towards technological risk and benefits. Policy Sciences, 8, 127-152.

Johnson, E. J., \& Tversky, A. (1983). Affect, generalization, and perception of risk. Journal of Personality and Social Psychology, 45, 20-31.

Johnson, E. C., \& Tversky, A. (1984). Representations of perceptions of risk. Journal of Experimental Psychology: General, 113, 55-70.

Lai, C. J., Brennan, A. Chan, H., \& Tao, J. (2003) Disposition toward environmental hazards in Hong Kong Chinese: validation of a Chinese version of the environmental appraisal inventory. Journal of Environmental Psychology, 23, 369-384. 
Morgan, M. G., Florig, H. K., DeKay, M. L., \& Fischbeck, P. (2000). Categorizing risks for risk ranking. Risk Analysis, 20, 49-58.

Neto, F., \& Mullet, E. (2000). Societal risks as seen by the Portuguese public. European Review of Applied Psychology, 50, 155-163

Puy, A. (1995). Percepción social de los riesgos. Madrid. Fundación Mapfre.

Puy, A., \& Aragonés, J. I. (1992). Risk dimensions in the perception of personal risk exposure. In M. Aristides \& C. Karaletscu (Eds.), Socio-environmental metamorphoses (Proceedings IAPS 12 International Conference, vol. II, pp. 309-314). Salónica: Aristotle University of Thessaloniki.

Puy, A., \& Cortés, B.(2000). Percepción social de los riesgos y comportamiento en los desastres. In J. I. Aragonés \& M. Amérigo (Comps.), Psicología ambiental (2 ${ }^{\text {nd }}$ ed., pp. 381402). Madrid: Pirámide.

Slovic, P. (1987). The perception of risk. Science, 236, 280-285.
Slovic, P. (1992). Perception of risk: Reflections on the psychometric aradigm. In S. Krimsky \& D. Golding (Eds.), Social theories of risk (pp. 117-152). Westport, CO: Praeger. Slovic, P. (Ed.). (2000a). The perception of risk. London: Earthscan. Slovic, P. (2000b). Perception of risk from radiation. In P. Slovic (Ed.), The perception of risk (pp. 264-274). London: Earthscan.

Slovic, P., Fischhoff, B., \& Lichtenstein, S. (1986). The psychometric study of perceptión of risk. In V. T. Covello, J. Menkes, \& J. Mumpower (Eds.), Risk evaluation and management (pp. 3-24). London: Plenum Press.

Vlek, C., \& Stallen, P. J. (1981). Judging risk and benefits in the small and in the large. Organizational Behavior and Human Performance, 28, 235-271.

Received January, 9, 2006 Revision received June, 1, 2007

Accepted June, 15, 2007 